\title{
IDADE ÓTIMA DE APOSENTADORIA NO RGPS: UMA ANÁLISE SOB A PERSPECTIVA DA MAXIMIZAÇÃO DOS BENEFÍCIOS FUTUROS ESPERADOS ${ }^{1}$
}

\section{OPTIMAL RETIREMENT AGEIN THE RGPS: AN ANALYSIS UNDER THE PERSPECTIVE OF THE EXPECTED FUTURE BENEFITS MAXIMIZATION}

\author{
Fernando Guedes de Campos ${ }^{2}$ \\ Graduado em Ciências Atuariais pela Universidade Federal de Pernambuco (UFPE)
}

fernandoguedes.c@gmail.com

Filipe Costa de Souza

Doutor em Economia pela Universidade Federal de Pernambuco (PIMES/UFPE)

Professor do Departamento de Ciências Contábeis e Atuariais da Universidade Federal de Pernambuco (UFPE)

filipecostadesouza@hotmail.com

\section{RESUMO}

Este estudo objetivou encontrar, sob a perspectiva atuarial, a idade de aposentadoria que maximiza o valor presente dos benefícios futuros esperados de um trabalhador vinculado ao Regime Geral de Previdência Social (RGPS). Assumindo hipóteses e realizando simulações, o estudo leva em conta fatores sociais, legislativos, econômicos e atuariais utilizados no cálculo do valor presente dos benefícios futuros esperados de um trabalhador, tais como: sexo, idade de entrada no mercado de trabalho, taxa de juros, taxa de crescimento salarial, expectativa de sobrevida e inflação. Cenários foram elaborados e analisados de acordo com as alterações recentes nas regras de aposentadoria do RGPS, indicando o impacto que esses fatores exercem sob a idade ótima de aposentadoria. Tomando como base as premissas iniciais do estudo, os resultados apontam que as idades de aposentadoria que maximizam o fluxo de benefícios futuros esperados são de 57 anos para homens e 52 anos para mulheres, e estas idades ótimas ocorrem no momento em que os segurados preenchem os requisitos para aposentadoria pela Regra 85/95. De acordo com a análise de sensibilidade, conclui-se que variações na expectativa de vida ao nascer não alteram significativamente a idade ótima de aposentadoria, diferentemente das taxas de juros e de crescimento salarial, que apresentaram maiores impactos nessas idades ótimas. Ademais, o fato da elegibilidade para aposentadoria por tempo de contribuição ocorrer 5 anos mais cedo para contribuintes do sexo feminino, atrelado ao fato da bonificação de 5 anos de contribuição para o cálculo do fator previdenciário, faz com que a idade que maximiza o fluxo de benefícios futuros esperados para mulheres seja sempre menor do que para homens. Essa diferença também ocorre nos valores dos montantes esperados que, por tais fatos, são sempre maiores para contribuintes do sexo feminino.

Palavras-chave: RGPS; Matemática Atuarial; Aposentadoria; Regra 85/95.

\footnotetext{
${ }^{1}$ Artigo recebido em: 12/08/2016. Revisado por pares em: 18/09/2016. Versão final recebida em: 04/10/2016. Recomendado para publicação em: 12/10/2016 por Luiz Felipe de Araújo Pontes Girão (Editor Adjunto). Publicado em: 28/10/2016. Organização responsável pelo periódico: UFPB.

${ }^{2}$ Endereço: Av. Prof. Moraes Rego, 1235, Cidade Universitária, UFPE/CCSA/DCCA, CEP: 50.670-901, Recife/PE. DOI: http://dx.doi.org/10.18405/recfin20160306
} 


\section{ABSTRACT}

This study aimed to find, under the actuarial perspective, the retirement age that maximizes the expected present value of the future benefits cash flow of a worker linked to The Brazilian General Social Welfare Policy (RGPS). Assuming certain hypothesis and making simulations, the study deals with social, legislative, economics and actuarial factors used to calculate the expected present value of the future benefits cash flow, such as: gender, age of entrance into the labor market, interest rate, wage growth rate, life expectance and inflation rate. Scenarios were developed and analyzed in accordance to the recent changes in the retirement rules of the RGPS, indicating the impact that these factors have on the optimal retirement age. Based on the initial assumptions of the study, the results revealed that the retirement ages that maximize the expected present value of the future benefits cash flow are 57 years for men and 52 years for women, and these optimal ages occur when the workers meet the requirements of the 85/95 rule. According to the sensitivity analysis, it was concluded that variations in the life expectancy at birth did not significantly alter the optimal retirement age, different from the interest rate and wage growth rate, which had greater impact in these optimal ages. Moreover, the fact that the requirements for retirement due to contribution time occur five years earlier for female contributors, linked to a five-year bonus in the reduction factor calculation, makes that the optimal retirement age for women be always lower than for men. This difference also occurs with respect to the expected present values of the future benefits cash flows which, for such facts, are always higher for female contributors.

Keywords: RGPS; Actuarial Mathematics; Retirement; 85/95 Rule.

\section{INTRODUÇÃO}

O sistema previdenciário é pauta nos principais governos do mundo. Soluções e estratégias são debatidas diariamente para torná-los equilibrados e sustentáveis sem que ocorra grandes ônus econômicos, tanto para os empregados e empregadores (contribuintes) quanto para o segurador (governo). No Brasil não é diferente, mesmo após a promulgação da Constituição Federal de 1988, o país passou por diversas reformas previdenciárias, visando sempre o equilíbrio das contas públicas e a garantia da manutenção do poder aquisitivo da população que perde sua capacidade laboral no decorrer dos anos. Qualquer decisão nesse âmbito deve ser pensada cautelosamente, tanto por parte dos poderes da república, quanto pelos trabalhadores que contribuem todo mês parte de seu salário visando uma aposentadoria digna.

Para Magalhães et al. (2004), o trabalho é um atributo relevante na identidade individual, como o nome, o sexo e a nacionalidade. Principalmente na cultura ocidental, o trabalho é um dos pilares da autoestima, identidade e senso de utilidade. A participação em atividades sociais parece não ser tão importante no estabelecimento da identidade ou status social quanto o trabalho, por isso, a interrupção de atividades profissionais e a perda dos vínculos sociais ali estabelecidos podem trazer dificuldades capazes de ameaçar a qualidade de vida dos indivíduos.

No Brasil, a aposentadoria por tempo de contribuição é solicitada em média aos 54 anos de idade, porém, com o intuito de aumentar essa idade para 58, no dia 05 de novembro de 2015, a então Presidenta da República Dilma Rousseff sancionou a Lei 13.183 (regra 85/95 progressiva), que mudou as regras de aposentadoria do Regime Geral de Previdência Social - RGPS. A nova regra leva em conta a soma da idade com o tempo de contribuição do trabalhador, sendo necessário para obtenção do benefício integral de aposentadoria, que essa soma resulte em 85 para mulheres e 95 para homens. A Lei 13.183/2015, visando acompanhar o crescimento da expectativa de vida da população, prevê que o cálculo da soma da idade com o tempo de contribuição seja progressivo, requisitando do contribuinte uma totalização maior no decorrer dos anos (como será abordado com mais detalhes no Capítulo 2). 
O objetivo da nova regra, além de diminuir o déficit nas contas da previdência social, previsto pelo ministério do planejamento em $\mathrm{R} \$ 7$ trilhões até 2060, é encontrar uma alternativa ao fator previdenciário, mecanismo que reduz o valor do benefício para quem se aposentar por tempo de contribuição antes de atingir 65 anos (no caso de homens) e 60 (no caso de mulheres) 3 .

Conforme aponta Brown (2008), critérios econômico-atuariais podem levar a um entendimento mais pontual do problema e servir como base para a construção de políticas previdenciárias mais sólidas. Contudo, tais preceitos, também podem ser utilizados no momento de analisar algumas variáveis envolvidas na escolha do contribuinte entre se aposentar ou continuar trabalhando. A experiência de aposentadoria interliga aspectos econômicos, familiares e individuais (GEORGE, 1996). Porém, o estudo em questão, leva em conta apenas o ponto de vista econômico-atuarial, assumindo algumas hipóteses e modelando fórmulas para diversos contextos matemáticos e legislativos.

Se por um lado o governo tenta diminuir o déficit financeiro e atuarial nas contas da previdência, os contribuintes buscam soluções para se adequar aos diferentes cenários legislativos envolvidos no momento de sua aposentadoria. Diante de tantas variáveis e contextos, este estudo busca responder as seguintes questões: Qual é a idade de aposentadoria que maximiza atuarialmente o fluxo dos benefícios dos trabalhadores vinculados ao RGPS? Quais os impactos que as premissas do modelo - tais como taxa de juros, expectativa de vida entre outras - causam na idade ótima de aposentadoria? Que influência as mudanças recentes na legislação previdenciária têm sob a idade ótima de aposentadoria? Assim, os objetivos centrais deste estudo são: i) encontrar, sob a ótica da matemática atuarial, dentre as possíveis idades de aposentadoria para um trabalhador vinculado ao RGPS, a idade que resulta em um maior Valor Presente Esperado dos Benefícios Futuros; ii) realizar uma análise de sensibilidade dos parâmetros do modelos de modo a avaliar o impacto que alterações em tais parâmetros acarretam na idade ótima de aposentadoria $\left(x^{*}\right)$ e, por fim, iii) comparar de forma crítica as regras de aposentadoria do fator previdenciário e a regra 85/95 progressiva, bem como, os reflexos sobre trabalhadores do sexo masculino e feminino.

Vale ressaltar que encontrar a idade ideal para a aposentadoria vai muito além de um cálculo matemático, porém, espera-se que com auxílio deste, possam-se obter informações importantes a respeito da decisão do instante em que um trabalhador deve se aposentar.

O estudo possui mais cinco capítulos. No Capítulo 2 apresenta-se a estrutura previdenciária brasileira, colocando em evidência o RGPS, expondo sua história e as principais reformas estruturais e legislativas ocorridas desde a sua criação. O Capítulo 3 contém o modelo atuarial utilizado para o cálculo da idade ótima de aposentadoria que maximiza o fluxo de benefícios esperados, bem como as hipóteses e premissas utilizadas. No Capítulo 4 são expostos e discutidos os principais resultados da pesquisa, e realizada uma análise de sensibilidade dos parâmetros (premissas) inicialmente adotados no modelo. O quinto e último capítulo contém as conclusões do estudo.

\section{REFERECIAL TEÓRICO}

\subsection{Uma Brevíssima História da Previdência Social Brasileira}

Conforme aponta Pinto (2010), o primeiro registro acerca da aposentadoria no Brasil ocorreu através do Decreto de 01 de outubro de 1821 promulgado por Dom Pedro de Alcântara, que concedeu aposentadoria aos mestres e professores após 30 anos de serviço, assegurando também, abono de $1 / 4$ dos ganhos aos que continuassem em atividade. Porém, o ponto de partida para o surgimento da Instituição da Previdência Social no Brasil foi o decreto $n^{\circ} 4.682$ de 24 de janeiro de 1923, conhecida como lei Eloy Chaves, que determinou a criação de uma caixa de Aposentadoria e Pensões para os empregados das empresas ferroviárias (SERRA; GURGEL, 2008). Nos anos 1930, Getúlio Vargas reestruturou a Previdência Social, incorporando praticamente todas as categorias de trabalhadores

\footnotetext{
${ }_{3}$ Ver: http://www.camara.leg.br/internet/comissao/index/mista/orca/ldo/LDO2016/proposta/anexoIV_6.pdf.
} 
urbanos. Somente em 1963 o trabalhador do campo é incluído no sistema previdenciário e com a Constituição de 1988 esse benefício é estendido a todos trabalhadores (CUT, 1989). Na década de 1930, através da promulgação de diversas normas, os benefícios sociais começaram a ser implementados para a maioria das categorias de trabalhadores dos setores público e privado. Seis institutos de previdência foram criados com o intuito de gerir e efetivar a seguridade social brasileira.

No dia 26 de agosto de 1960, a Lei n 3.807 instituiu a Lei Orgânica da Previdência Social (LOPS), sua principal mudança foi a unificação das leis que regiam os Institutos de Aposentadorias e Pensões até então instituídos. Formava-se assim, para os trabalhadores do setor privado, um único sistema de previdência em 1966, o Instituto Nacional de Previdência Social (INPS), além da criação do Fundo de Garantia por Tempo de Serviço (FGTS). Em 1969 houve a ampliação da cobertura previdenciária contemplando os empregados domésticos e trabalhadores rurais, bem como profissionais autônomos (COUTO, 2000).

No ano de 1974 foi instaurado o Ministério da Previdência e Assistência Social, antes as atribuições ligadas às obrigações previdenciárias ficavam sob responsabilidade do Ministério do Trabalho e Emprego, na época chamado de Ministério do Trabalho e Previdência Social (MONTEIRO, 2014). Após a promulgação da Constituição Federal de 1988 os benefícios da previdência se estenderam a todos os trabalhadores, passando a garantir rendas mensais e vitalícias aos idosos e portadores de deficiência, desde que comprovada a baixa renda e que se enquadrassem na qualidade de segurado. Em 1990, o INPS passou a ser chamado de INSS (Instituto Nacional de Seguridade Social).

\subsection{Estrutura da Previdência Social Brasileira}

O Artigo 194 da Constituição Federal de 1988 conceitua a Seguridade Social como "um conjunto integrado de ações de iniciativa dos Poderes Públicos e da sociedade, destinadas a assegurar os direitos relativos à saúde, à previdência e à assistência social". Para Castro e Lazzari (2012, p. 58) a previdência social é: “O ramo de atuação estatal que visa a proteção de todo indivíduo atarefado numa atividade laborativa remunerada, para proteção de riscos decorrentes de perda ou redução, permanente ou temporária, das condições de obter seu próprio sustento".

Quanto à forma de financiamento, Filippo (2007) entende que existem dois tipos de sistemas: os contributivos e os não contributivos. Sendo os sistemas contributivos aqueles que o segurado contribui diretamente, na expectativa de obter um benefício no futuro. Já o sistema não contributivo, é o sistema que não exige do beneficiário uma contribuição direta. Sendo a previdência social, um seguro de filiação obrigatória, é também o único sistema de caráter contributivo dentre os seguros sociais assegurados no Brasil, conforme aponta o Artigo 201 da Constituição Federal: "A previdência social será organizada sob a forma de regime geral, de caráter contributivo e de filiação obrigatória, observados critérios que preservem o equilíbrio financeiro e atuarial". A previdência social está dividida em três grandes segmentos:

1) Regime Geral de Previdência Social (RGPS): Operado pelo INSS e de filiação obrigatória para os trabalhadores regidos pela Consolidação das Leis Trabalhistas (CLT).

2) Regime Próprio de Previdência Social: Instituído por entidades públicas, Institutos de Previdência ou Fundos Previdenciários e de filiação obrigatória para os servidores públicos titulares de cargos efetivos da União, dos Estados, do Distrito Federal e dos Municípios.

3) Regime de Previdência Complementar: Operado por Entidades Abertas e Fechadas de Previdência Complementar, regime privado, com filiação facultativa, criado com a finalidade de proporcionar uma renda adicional ao trabalhador.

\subsection{Principais Reformas do RGPS Após a Constituição de 1988}

Segundo Oliva (2013), o aumento da expectativa de vida foi um dos principais fatores que ocasionaram as alterações sofridas pela previdência social. As reformas promovidas através das 
Emendas Constitucionais (EC) nº20/98, nº41/2003, nº47/2005 e nº70/2012 tiveram, entre outros objetivos, sanar a discrepância existente entre o tempo de contribuição do segurado e sua expectativa de vida. No presente estudo, serão abordadas apenas as reformas que impactaram o RGPS.

\subsubsection{Emenda Constitucional no $20 / 98$}

Motivada por diversas razões, entre elas, o aumento da expectativa de vida, redução da taxa de natalidade, aumento do mercado de trabalho informal, concessão de benefícios sem fontes de custeio e ausência de estudos atuariais, a EC nº 20/98 procurou trazer um equilíbrio financeiro e atuarial já previsto anteriormente na legislação brasileira (BRASIL, 2002). As principais mudanças que a reforma encaminhou foram o aumento do tempo necessário para aposentadoria, separação das despesas de saúde e da previdência, vedação de acumulo de proventos e pensões e tempo de serviço passando a ser contado como tempo de contribuição. Através desta reforma, foi estipulada a aposentadoria por tempo de contribuição, extinguindo assim, a aposentadoria por tempo de serviço, passando-se a exigir 35 anos de contribuição para homens e 30 para mulheres. Além da destinação do salário-família e do auxílio-reclusão apenas ao dependente do segurado que comprovar baixa renda (BARBOSA, 2013).

Outras mudanças substanciais trazidas pela EC nํ20/98, foram a instituição de idade mínima exigida para solicitação de aposentadoria proporcional, ficando em 48 anos para mulheres e 53 anos para homens; o estabelecimento de um teto nominal para os benefícios no valor de $\mathrm{R} \$ 1.200,00$ e o fim das aposentadorias especiais, aquelas em que o tempo de serviço ou de contribuição exigido é menor em relação aos demais trabalhadores, salvo apenas professores que comprovem tempo exclusivo de exercício na função de magistério no ensino infantil, fundamental e médio, além de trabalhadores expostos a agentes nocivos à saúde (SALVADOR, 2005). O Art. 201, § $4^{\circ}$, da Constituição Federal estabelece que os benefícios previdenciários devem ser reajustados de forma a preservar em caráter permanente seu valor real, mas não são fixadas regras operacionais em relação ao índice de reajuste nem a periodicidade dessa correção.

Kertzman (2011, p. 44) complementa,

“A EC 20/98 deu destinação específica à previdência e assistência do produto arrecadado pelo INSS, reestruturou a previdência do servidor público, passou a executar e cobrar as contribuições pela Justiça do Trabalho, em relação às suas sentenças e reduziu em 5 anos a aposentadoria do professor universitário".

Após a referida Emenda, estabeleceu-se ainda a Lei 9.876/99, que instituiu o fator previdenciário, com o objetivo de reduzir o benefício das pessoas que desejam se aposentar por tempo de contribuição antes de atingir 65 anos no caso de homens e 60 no caso de mulheres, incentivando os segurados a continuarem a contribuir até atingir a integralidade do benefício. Para Barbosa (2013), o fator consiste numa mudança na forma de cálculo dos benefícios, variando em razão do tempo de contribuição (Tc), idade no momento da aposentadoria (Id) e expectativa de sobrevida do segurado (Es). O fator previdenciário, f, é dado pela Equação 1.

$$
f=\frac{\alpha \cdot T c}{E s}\left(1+\frac{I d+T c \cdot \alpha}{100}\right)
$$

Em que,

$$
\begin{aligned}
& \alpha=\text { Alíquota de contribuição (fixada em } 0,31 \text { ); } \\
& \text { Tc = Tempo de contribuição; } \\
& \text { Es = Expectativa de sobrevida na data da aposentadoria; } \\
& \text { Id = Idade no momento da aposentadoria. }
\end{aligned}
$$


A Lei 9.876/99 concede um bônus de cinco anos no tempo de contribuição segundo o cálculo do fator para as mulheres, ou seja, se uma mulher deseja se aposentar no momento em que totaliza 30 anos de contribuição, o cálculo do fator será feito com base no tempo de contribuição de 35 anos (PENAFIERI; AFONSO, 2013). Portanto, utilizando as expectativas de sobrevida da Tábua Completa de Mortalidade IBGE 2014, para uma mulher e um homem, ambos com 57 anos de idade e 35 anos de contribuição, o valor dos respectivos fatores são 0,86 e 0,75 . Porém, a fórmula do fator nem sempre resulta em uma redução no benefício do contribuinte, isto é, casos em que o fator é maior do que ou igual a 1 também são possíveis, desde que o valor do benefício não ultrapasse o estabelecido pelo teto previdenciário.

Para Nolasco (2012), após o advento da Lei 9.876/99, o valor do benefício passou a ser calculado pela média aritmética real dos $80 \%$ maiores salários de contribuição de todo período contributivo do segurado, multiplicado pelo fator previdenciário. Portando, o valor do benefício, B, é dado pela Equação 2.

$$
B=M f
$$

Em que,

M = Média aritmética real dos $80 \%$ maiores salários de contribuição;

$\mathrm{f}=$ Fator previdenciário.

\subsubsection{Fórmula $85 / 95$ Progressiva}

No dia 05 de novembro de 2015, com o sancionamento da Lei 13.183, as regras de aposentadoria do RGPS mudaram mais uma vez. A fórmula 85/95 progressiva veio à tona, na expectativa de diminuir o déficit financeiro e atuarial da previdência social e, também, como alternativa ao fator previdenciário. Os números 85 e 95 representam a soma da idade com o tempo de contribuição do contribuinte, sendo necessário para a obtenção do benefício integral (sem a aplicação do fator previdenciário), que mulheres totalizem 85 e os homens 95.

No entanto, visando acompanhar o aumento da expectativa de vida dos brasileiros, a nova fórmula prevê aumentos progressivos nessa totalização. A partir do dia 31 de dezembro de 2018, para adquirir o benefício integral, a soma da idade com o tempo de contribuição terá unidades extras de acordo com o ano em que o trabalhador desejar se aposentar, ou seja, para se aposentar em 2019 ou 2020, o contribuinte deverá somar uma unidade à Regra 85/95, que passará a ser 86/96. No caso das pessoas que queiram se aposentar entre 2021 e 2022, soma-se dois pontos, chegando a 87/97 e assim por diante até 2026, quando para homens será necessário atingir 100 pontos e as mulheres 90 , como ilustra a Tabela 1. Além da progressão na fórmula, é exigido um tempo mínimo de contribuição, sendo, 30 anos para as mulheres e 35 para os homens.

Professores que se dedicarem exclusivamente ao ensino infantil, fundamental ou médio, ganham uma bonificação de cinco unidades na soma da idade com o tempo de contribuição. A nova regra vale apenas para as pessoas que desejam auferir a aposentadoria por tempo de contribuição na hipótese de requerimento de benefício pelo valor integral, ou seja, isento da aplicação do fator previdenciário. No entanto, se o segurado pretende se aposentar antes de completar a totalização mínima exigida pela fórmula, ele poderá requerer o benefício, mas nesse caso, o fator previdenciário será aplicado, como visto em na Equação 2, importando na possível redução do benefício.

Portanto, um indivíduo que preencher o requisito de aposentadoria por tempo de contribuição e atingir a soma necessária para se aposentar através da Regra 85/95 poderá optar pela não aplicação do fator previdenciário no cálculo do seu benefício. Deste modo, o trabalhador terá o salário de benefício de aposentadoria, B, calculado através da equação (2), sem a aplicação do fator previdenciário, utilizando apenas a média aritmética real dos $80 \%$ maiores salários de contribuição. 
Tabela 1 - Quadro da progressividade da fórmula 85/95.

\begin{tabular}{ccc}
\hline Ano & $\begin{array}{c}\text { Totalização mínima } \\
\text { exigida (mulheres) }\end{array}$ & $\begin{array}{c}\text { Totalização mínima } \\
\text { exigida (homens) }\end{array}$ \\
\hline 2016 até 2018 & 85 & 95 \\
2019 até 2020 & 86 & 96 \\
2021 até 2022 & 87 & 97 \\
2023 até 2024 & 88 & 98 \\
2025 até 2026 & 89 & 99 \\
A partir de 2027 & 90 & 100 \\
\hline
\end{tabular}

\section{O MODELO}

Com o objetivo de encontrar a idade de aposentadoria, $x^{*}$, que maximiza atuarialmente o fluxo dos benefícios esperados de um trabalhador caracterizado na forma de segurado no RGPS, serão apresentadas inicialmente como variáveis do modelo, a idade de entrada do segurado no mercado de trabalho, $\mathrm{y}$, e a idade em que o segurado se torna elegível para aposentadoria por tempo de contribuição, x. Assim, conforme a EC no 20/98, para homens $x=y+35$ e para mulheres $x=y+30$.

A idade $x$ será usada como data focal para o modelo, vista como a idade em que o segurado adquire o direito de se aposentar, a partir dela, será calculado atuarialmente, para cada ano a mais de espera, t, o Valor Presente Esperado dos Benefícios Futuros (VPEBF). Após comparar os montantes, a idade ótima de aposentadoria, $x^{*}$, será definida como a idade de aposentadoria que corresponde a um maior VPEBF. O Art. 51 da Lei $n^{\circ} 8.213 / 91$ prevê a aposentadoria compulsória para contribuintes vinculados ao RGPS como sendo 70 anos para homens e 65 para mulheres, portanto, o valor de $t$ irá variar entre 0 (contexto onde o segurado se aposenta por tempo de contribuição no momento da sua elegibilidade) e o momento de aposentadoria compulsória.

Para realizar os cálculos da média aritmética real dos $80 \%$ maiores salários de contribuição e do respectivo VPEBF, será, por simplicidade, suposto que os salários de contribuição e os recolhimentos junto ao RGPS são consumados de forma anual, no início de cada período e de modo contínuo desde o momento de entrada do segurado no mercado de trabalho até o instante da sua aposentadoria. Importante também, para a elaboração das fórmulas, a suposição de que o segurado entra no mercado de trabalho, assim como, se aposenta, apenas no primeiro dia do ano.

Será ilustrado inicialmente o diagrama do fluxo anual dos salários de contribuição do segurado e a fórmula utilizada para o cálculo da média aritmética real dos $80 \%$ maiores salários de contribuição, obedecendo às taxas de crescimento salarial, w, e de inflação, j, previamente estabelecidas. No segundo instante será exposto o fluxo dos benefícios de aposentadoria em função do tempo t. Posteriormente, a partir da idade focal, $x$, e de uma taxa de juros, i, pré-estabelecida, será exposto a expressão encontrada para o cálculo do VPEBF de acordo com a idade de aposentadoria analisada $(x+t)$, definindo também, conforme as regras vigentes de aposentadoria, quais benefícios terão a incidência do fator previdenciário e quais estarão isentos de sua aplicação. Por último, será ilustrado um quadro comparativo entre os diferentes VPEBF encontrados, de acordo com o tempo $t$ (em anos), que o contribuinte analisa esperar para se aposentar após se tornar elegível.

\subsection{Fluxo dos Salários de Contribuição}

Para fins de simplificação nos cálculos e para o uso da tabela de progressividade da regra de aposentadoria 85/95, será usada a hipótese de que o segurado se tornará elegível para aposentadoria por tempo de contribuição em 01 de janeiro de 2016, e a partir daí, efetivando sua aposentadoria apenas no primeiro dia do ano $\mathrm{x}+\mathrm{t}$ em análise. Supondo também que na idade focal $\mathrm{x}$, o salário anual do segurado é igual a $\mathrm{S}$, com taxa de crescimento salarial anual w. A Figura 1 apresenta o diagrama do fluxo de caixa dos salários de contribuição do segurado, desde a sua idade de entrada no mercado de trabalho, $\mathrm{y}$, até a idade de aposentadoria analisada, $\mathrm{x}+\mathrm{t}$. 
Figura 1 - Diagrama de fluxo de caixa: Salários de contribuição.

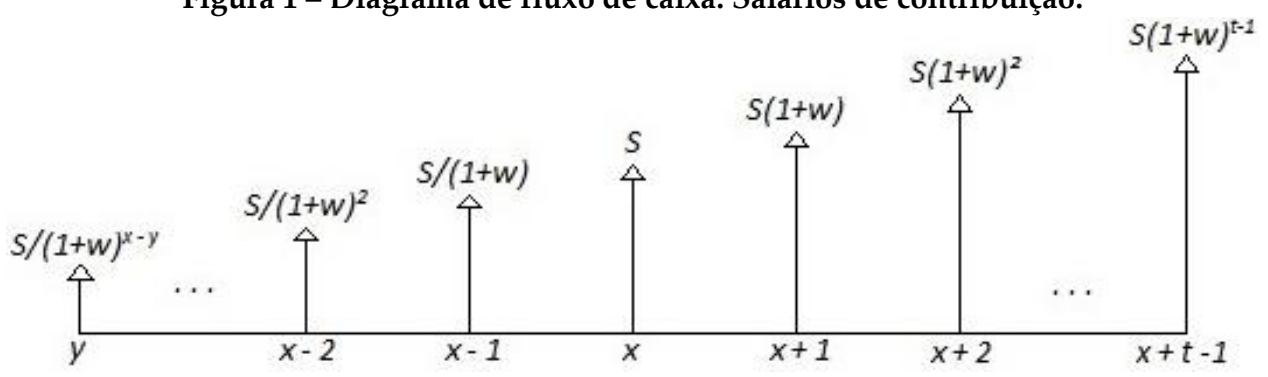

Considerando que o contribuinte não realiza nenhuma contribuição ou recebe salário no ano em que se aposenta, recebendo apenas o valor do benefício, $B_{t}$, no início do ano, o cálculo da média aritmética real dos $80 \%$ maiores salários de contribuição na idade $\mathrm{x}+\mathrm{t}$, se dá pela Equação 3, adaptada de (GIAMBIAGI; AFONSO, 2009) para um contexto inflacionário. Sendo t a quantidade de anos que se passam depois da elegibilidade do segurado, T o tempo total (em anos) de contribuição e, i e $\mathrm{j}$, as taxas de juros e inflação, respectivamente.

$$
M_{t}=\frac{S}{0,8 T} \sum_{k=1}^{0,8 T} \frac{(1+j)^{k}}{(1+w)^{k-t}}
$$

\subsection{Fluxo dos Salários de Benefício}

Nesta seção, usa-se a suposição de que o salário de benefício, $B_{t}$, será pago imediatamente ao segurado, a partir, e no início da idade $x+t$ (idade que o contribuinte optar pela aposentadoria), sendo corrigido anualmente pela taxa de inflação, j. Portanto, existirá um fluxo e um VPEBF distinto para cada valor de t. Logo, no momento em que o segurado optar pela aposentadoria, receberá imediatamente e, no início do ano correspondente, o salário de benefício $B_{t}$, calculado através de (2), de acordo com a regra de aposentadoria em que o contribuinte se enquadrará. A Figura 2 ilustra o fluxo dos salários de benefício, para $\mathrm{t}=0$ :

Figura 2 - Diagrama do fluxo de caixa: Salários de benefício, para $t=0$.

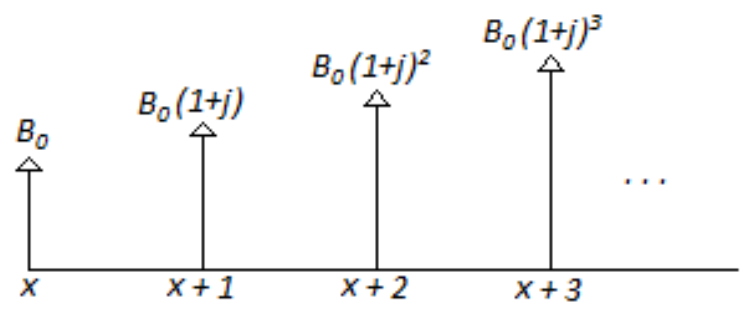

A Figura 3 representa o fluxo dos salários de benefício para opção de o segurado aguardar um ano, além do necessário para se aposentar $(\mathrm{t}=1)$, visando, por exemplo, alterar a regra de cálculo do seu benefício $B_{t}$, e assim por diante, como ilustra a Figura 4.

Figura 3 - Diagrama do fluxo de caixa: Salários de benefício, para $t=1$.

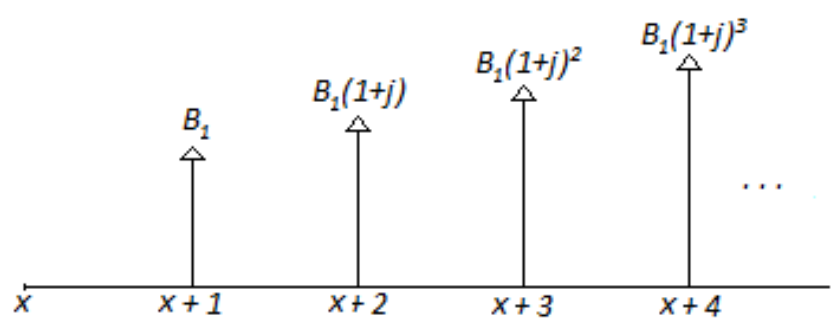


Figura 4 - Diagrama do fluxo de caixa: Salários de benefício, caso geral.

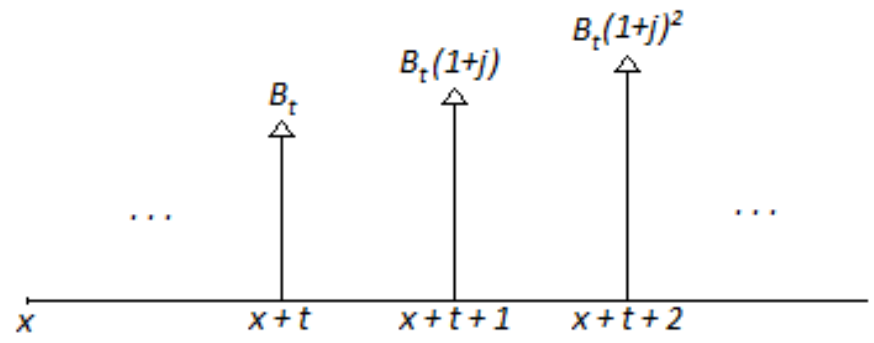

\subsection{Cálculo do VPEBF}

Para realizar as comparações entre os montantes dos salários de benefícios futuros esperados para cada idade a partir de $\mathrm{x}$, foram extraídas da Tábua Completa de Mortalidade para ambos os sexos - IBGE 2013 (extrapolada para idades acima de 80 anos e desagravada em 2,10\%), as probabilidades de vida, assim como, as expectativas de sobrevida. Sendo $l_{x}$ a quantidade de pessoas vivas na idade x (extraído da referida tábua) e $D_{x}=v^{x} l_{x}$, com $v=(1+i)^{-1}$. Será realizado primeiramente, através da Equação 4, para cada valor possível de t, o cálculo do VPEBF do contribuinte. Posteriormente, sob esses valores, incidirá de acordo com as características do segurado na idade de aposentadoria em análise $(\mathrm{x}+\mathrm{t})$, a média aritmética real dos $80 \%$ maiores salários de contribuição e a aplicação do fator previdenciário, se necessário. A partir daí, tornando possível a comparação entre os VPEBF, visando encontrar dentre eles, o que resultará em um maior montante e, consequentemente, a idade ótima de aposentadoria correspondente.

$$
V P E B F_{t}=\frac{B_{t} \sum_{k=0}^{\infty} D_{x+t+k}(1+j)^{k}}{D_{x}}
$$

\subsection{Premissas do Modelo}

Para a realização deste estudo, é necessário supor algumas hipóteses para o cenário inicial. Será considerada como idade de entrada do indivíduo no mercado de trabalho na qualidade de segurado, y, a idade de 18 anos, momento em que recebe o primeiro salário e, com efeito, realiza a primeira contribuição junto ao RGPS, a partir de então, contribuindo de forma ininterrupta até o momento de sua aposentadoria. Deve-se também ter em conta, que a regra de aposentadoria por tempo de contribuição prevê a necessidade de 35 anos de contribuição para o homem e 30 para a mulher. Portanto, a idade de elegibilidade e idade focal do estudo, $x$, será de 53 anos para homens $(y+35)$ e 48 anos para as mulheres $(y+30)$.

Com relação às taxas de crescimento salarial anual do segurado, $w$, e de juros, i, serão utilizadas as mesmas encontradas por Giambiagi \& Afonso (2009), sendo w, estratificada por sexo, com, $1,97 \%$ a.a. para homens, e 1,29\% a.a. para as mulheres, quanto a i, será utilizada para o primeiro cenário, o valor real de $3 \%$ a.a. Para a taxa de inflação, j, será utilizada, a meta do governo ${ }^{4}$ no momento em que o presente estudo foi realizado, $4,5 \%$ a.a. O salário anual do segurado, $\mathrm{S}$, na idade focal $x$, será considerado igual à média salarial anual de trabalhadores de carteira assinada no Brasil em janeiro de 2016, R\$ 33.257,52, valor divulgado pelo IBGE em 23 de março de 2016.

Visto que a Tábua de Mortalidade mais recente divulgada pelo IBGE é a Tábua Completa de Mortalidade - IBGE 2014, que ainda não foi extrapolada pelo Ministério da Previdência Social (MPS) para idades acima de 80, o presente estudo optou, para realização dos cálculos, pelo uso da Tábua Completa de Mortalidade - IBGE 2013 para ambos os sexos, extrapolada para idades acima de 80

${ }^{4}$ Valor utilizado de acordo com resolução no 4.419 de 25 de junho de 2015 - Banco Central do Brasil. 
pelo MPS 5 . Porém, para diminuir distorções no cálculo dos montantes, a Tábua Completa de Mortalidade - IBGE 2013 (extrapolada) foi desagravada em 2,10\%, ou seja, reduzindo as probabilidades de morte da tábua em $2,10 \%$, de modo a aproximar a expectativa de vida ao nascer da respectiva (74,9 anos) àquela da Tábua Completa de Mortalidade - IBGE 2014 (75,2 anos). Com a desgravação, a diferença entre as expectativas de vida ao nascer pelas duas tábuas foi menor do que 1\% (3,65 dias).

Logo, de acordo com a atribuição dos valores para as varáveis do cenário inicial do modelo, temos:

- Idade de entrada no mercado de trabalho (y): 18 anos;

- Idade focal (x): 53 para homens e 48 para mulheres;

- Taxa de crescimento salarial (w): 1,97\% a.a. para homens e 1,29\% a.a. para mulheres;

- Taxa real de juros (i): 3\% a.a.;

- Taxa de inflação (j): 4,5\% a.a.;

- Salário anual na idade focal (S): R\$33.257,52;

- Tábua de mortalidade: Tábua Completa de Mortalidade para ambos os sexos - IBGE 2013, extrapolada pelo MPS para idades acima de 80 e desagravada em 2,10\%.

\section{RESULTADOS E SIMULAÇÕES}

Este capítulo terá como foco principal a apresentação e discussão dos resultados obtidos neste estudo e a análise de sensibilidade dos parâmetros, ou seja, uma avaliação do comportamento da variável resposta $\left(x^{*}\right)$, idade em que o fluxo dos benefícios futuros esperados de um trabalhador vinculado ao RGPS é maximizado, em razão de mudanças individuais em algumas premissas do modelo. Primeiramente, serão elaborados quadros e comentários a respeito do cenário inicial, indicando de acordo com as hipóteses expostas na Seção 3.4, os valores encontrados para $x^{*}$, tanto para segurados do sexo masculino, quanto para indivíduos do sexo feminino. Posteriormente, serão gerados e analisados novos resultados do estudo de acordo com alterações individuais nas variáveis: idade de entrada no mercado de trabalho (y), taxa real de juros (i), expectativa de vida ao nascer e taxa real de crescimento salarial $(\mathrm{w})$. Nas idades de aposentadoria em que o segurado poderá optar ou não pela aplicação do fator previdenciário, será escolhida a regra de aposentadoria (Regra 85/95 ou Regra do Fator) que resulta em um maior VPEBF, portanto, para as idades em que a Regra 85/95 resulta em um maior montante, o fator não será aplicado, indicado pelo sinal (-).

\subsection{Resultados}

De acordo com o cenário inicial estabelecido nas premissas do modelo, a Tabela 2 ilustra os VPEBF de um contribuinte homem, para cada ano a mais de espera, $t$, partindo de sua elegibilidade para aposentadoria por tempo de contribuição aos 53 anos, até a aposentadoria compulsória para homens, 70 anos.

Observando a Tabela 2, é possível identificar que um homem, caracterizado na forma de segurado no RGPS, de acordo com as premissas inicias expostas na Seção 3.4, maximiza seu fluxo de benefícios esperado 4 anos após torna-se elegível para aposentadoria por tempo de contribuição, ou seja, aos 57 anos de idade, totalizando um $\mathrm{VPEBF}_{4}$ igual à $\mathrm{R}$ \$390.220,93. Importante observar também, que a maximização ocorre no momento em que o segurado preenche os requisitos da regra de aposentadoria 85/95, que prevê que em 2020, para homens, será necessário para obtenção do benefício, $B_{t}$, integral (isento da aplicação do fator previdenciário), que a soma da idade com o tempo de contribuição totalize 96.

\footnotetext{
${ }^{5}$ Conforme estabelecido no Art. 6, Inciso I, da Portaria MPS no 403/2008, para avaliações atuariais com data focal a partir
} de 01 de agosto de 2015. 
Tabela 2 - VPEBF vs. Idade de aposentadoria - Homem

\begin{tabular}{cccccccc}
\hline Ano & Idade & $\boldsymbol{t}$ & $\boldsymbol{S}_{\boldsymbol{t}}$ & $\boldsymbol{B}_{\boldsymbol{t}}$ & $\mathbf{T}$ & Fator & $\mathbf{V P E B F}_{\mathbf{t}}$ \\
\hline 2016 & 53 & 0 & $33.257,52$ & $16.386,97$ & 35 & 0,65 & $301.415,33$ \\
2017 & 54 & 1 & $35.438,76$ & $18.656,61$ & 36 & 0,69 & $310.533,63$ \\
2018 & 55 & 2 & $37.763,07$ & $21.049,06$ & 37 & 0,74 & $316.674,63$ \\
2019 & 56 & 3 & $40.239,82$ & $23.745,58$ & 38 & 0,79 & $323.417,22$ \\
$\mathbf{2 0 2 0}$ & $\mathbf{5 7}$ & $\mathbf{4}$ & $\mathbf{4 2 . 8 7 9 , 0 1}$ & $\mathbf{3 1 . 8 6 2 , 3 1}$ & 39 & - & $390.220,93$ \\
2021 & 58 & 5 & $45.691,29$ & $33.655,88$ & 40 & - & $371.157,22$ \\
2022 & 59 & 6 & $48.688,02$ & $35.863,25$ & 41 & - & $355.630,76$ \\
2023 & 60 & 7 & $51.881,30$ & $38.803,66$ & 42 & 1,02 & $345.488,38$ \\
2024 & 61 & 8 & $55.284,01$ & $43.795,48$ & 43 & 1,09 & $349.562,41$ \\
2025 & 62 & 9 & $58.909,90$ & $49.443,84$ & 44 & 1,17 & $353.167,43$ \\
2026 & 63 & 10 & $62.773,59$ & $55.838,25$ & 45 & 1,25 & $356.326,20$ \\
2027 & 64 & 11 & $66.890,69$ & $63.625,22$ & 46 & 1,34 & $362.008,43$ \\
2028 & 65 & 12 & $71.277,81$ & $71.898,74$ & 47 & 1,43 & $364.023,32$ \\
2029 & 66 & 13 & $75.952,68$ & $81.279,20$ & 48 & 1,53 & $365.415,05$ \\
2030 & 67 & 14 & $80.934,15$ & $91.922,86$ & 49 & 1,64 & $366.091,97$ \\
2031 & 68 & 15 & $86.242,34$ & $104.004,99$ & 50 & 1,75 & $366.045,05$ \\
2032 & 69 & 16 & $91.898,67$ & $118.726,58$ & 51 & 1,88 & $368.396,70$ \\
2033 & 70 & 17 & $97.925,98$ & $134.437,10$ & 52 & 2,01 & $366.690,64$ \\
\hline & & & & & & & \\
\end{tabular}

O salário benefício de aposentadoria do contribuinte no momento da sua aposentadoria aos 57 anos, $B_{4}$, apesar de maximizar o VPEBF, representa uma taxa de reposição de apenas $74,31 \%$ do valor do salário que receberia se o indivíduo continuasse na ativa. Isso se explica ao fato da média aritmética real dos $80 \%$ maiores salários de contribuição, sempre reduzir o valor do benefício do segurado de acordo com as hipóteses supostas neste estudo, pois, o aumento salarial anual é constante e o maior salário recebido na vida laboral do segurado será sempre o último.

Entre as idades 53 e 56 anos, o benefício, $B_{t}$, é obrigatoriamente calculado com a aplicação do fator previdenciário, visto que o contribuinte ainda não preenche os requisitos para se aposentar integralmente pela regra de aposentadoria 85/95. Porém, aos 57 anos, o segurado atinge a totalização mínima necessária (idade mais tempo de contribuição) para a obtenção do benefício integral pela nova regra, com o respectivo VPEBF máximo igual à $\mathrm{R} \$ 390.220,93$. Nas idades 58 e 59 anos, optar pela regra de aposentadoria 85/95 continua sendo mais vantajoso para o contribuinte, pois segue isentando o fator previdenciário (que permanece assumindo valores menores do que 1) do cálculo do seu benefício, diferentemente das idades acima de 59, quando é mais vantajoso para o contribuinte optar pela aplicação do fator.

O Gráfico 1 representa a comparação entre o comportamento do VPEBF levando em conta a regra de aposentadoria 85/95 progressiva (em que o fator previdenciário não é aplicado quando o segurado atinge a totalização mínima necessária) e a forma antiga de cálculo (a regra do fator previdenciário), na qual o fator sempre é aplicado e cresce à medida em que o segurado trabalha por mais tempo, podendo assumir valores maiores do que 1. Esta comparação torna possível uma análise geral do impacto que a Regra 85/95 progressiva causa na idade ótima de aposentadoria, $x^{*}$.

Observando o Gráfico 1, é possível notar que a partir dos 60 anos de idade é mais vantajoso para o segurado optar pela regra do fator, visto que o fator previdenciário começa a assumir valores maiores do que 1, resultando em aumentos no cálculo de seu benefício, diferentemente da Regra 85/95, que segue ausentando o fator do cálculo. Analisando apenas a progressão do VPEBF de acordo com a regra do fator, nota-se que a maximização ocorreria aos 69 anos, com um montante esperado igual à $\mathrm{R} \$ 368.396,72$, momento em que o fator previdenciário atinge o valor de 1,89, ou 
seja, quase duplica o valor do benefício do segurado. A Tabela 3 ilustra a comparação entre os VPEBF, de acordo com as duas regras.

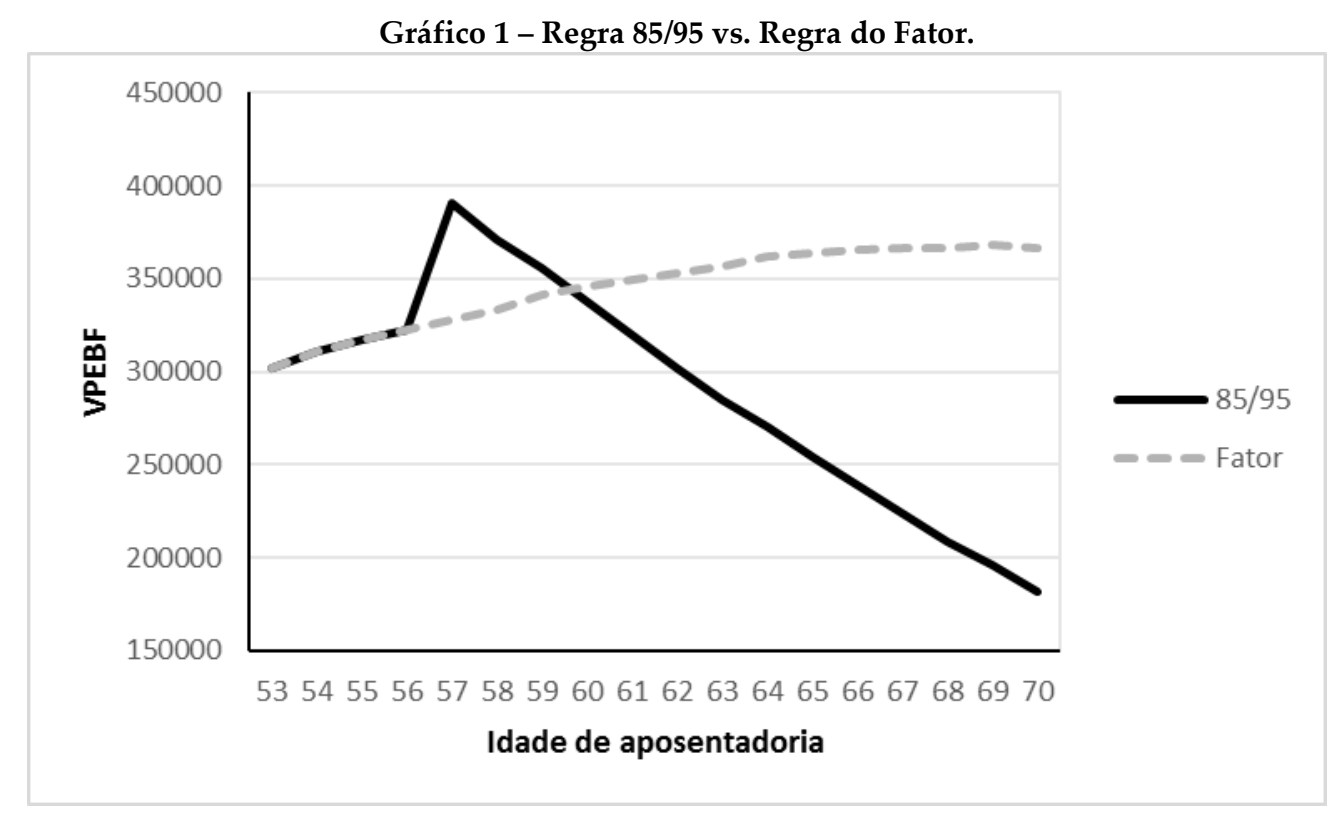

Descrita como alternativa ao fator previdenciário, a regra de aposentadoria 85/95 progressiva, de acordo com as premissas expostas na Seção 3.4, além de diminuir consideravelmente o tempo que o segurado leva para atingir a maximização do VPEBF, tem o montante esperado aproximadamente 5,92\% maior, do que o VPEBF máximo que seria alcançado se a aposentadoria fosse consumada apenas pela regra do fator previdenciário.

Tabela 3 - Regra 85/95 vs. Regra do Fator - Homem.

\begin{tabular}{ccccc}
\hline Idade & Fator (85/95) & VPEBF (85/95) & Fator & VPEBF \\
\hline 53 & 0,65 & $301.415,34$ & 0,65 & $301.415,34$ \\
54 & 0,69 & $310.533,64$ & 0,69 & $310.533,64$ \\
55 & 0,74 & $316.674,64$ & 0,74 & $316.674,64$ \\
56 & 0,79 & $323.417,22$ & 0,79 & $323.417,22$ \\
57 & - & $390.220,93$ & 0,84 & $328.052,32$ \\
58 & - & $371.157,05$ & 0,90 & $333.230,04$ \\
59 & - & $355.630,76$ & 0,96 & $341.014,47$ \\
60 & - & $337.293,21$ & 1,02 & $345.488,39$ \\
61 & - & $319.413,23$ & 1,09 & $349.562,42$ \\
62 & - & $301.960,50$ & 1,17 & $353.167,43$ \\
63 & - & $284.993,67$ & 1,25 & $356.326,20$ \\
64 & - & $270.767,99$ & 1,34 & $362.008,43$ \\
65 & - & $254.546,38$ & 1,43 & $364.023,33$ \\
66 & - & $238.797,87$ & 1,53 & $365.415,06$ \\
67 & - & $223.495,10$ & 1,64 & $366.091,98$ \\
68 & - & $208.676,50$ & 1,75 & $366.045,56$ \\
69 & - & $196.041,97$ & 1,89 & $368.396,72$ \\
70 & - & $182.081,82$ & 2,01 & $366.690,66$ \\
\hline
\end{tabular}


Ainda de acordo com o cenário inicial estabelecido nas premissas do modelo, a Tabela 4 ilustra os VPEBF de uma contribuinte mulher, para cada ano a mais de espera, $t$, partindo de sua elegibilidade para aposentadoria por tempo de contribuição aos 48 anos, até a aposentadoria compulsória para mulheres, 65 anos.

Conforme expõe a Tabela 4, é possível identificar que uma mulher, caracterizada na forma de segurada no RGPS, de acordo com as premissas inicias expostas na Seção 3.4, maximiza seu fluxo de benefícios esperados 4 anos após sua elegibilidade para aposentadoria por tempo de contribuição, ou seja, aos 52 anos de idade, totalizando um $\mathrm{VPEBF}_{4}$ igual à $\mathrm{R} \$ 479.415,49$, aproximadamente $22,85 \%$ maior do que o montante esperado pelo segurado homem, fato explicado pela maximização ocorrer 5 anos mais cedo. Importante observar também, que assim como no caso de contribuintes do sexo masculino, a maximização ocorre no momento em que a segurada preenche os requisitos da regra de aposentadoria 85/95, que prevê que em 2020, para mulheres, será necessário para obtenção do benefício, $B_{t}$, integral (isento da aplicação do fator previdenciário), que a soma da idade com o tempo de contribuição totalize 86 . O salário benefício de aposentadoria da contribuinte no momento da sua aposentadoria aos 52 anos, $B_{4}$, apesar de maximizar o VPEBF, representa uma taxa de reposição de $83,99 \%$ do valor do salário que receberia se o indivíduo continuasse na ativa, 9,68\% maior que a do contribuinte homem, devido ao crescimento salarial menos acentuado.

Tabela 4 - VPEBF vs. Idade de aposentadoria - Mulher.

\begin{tabular}{cccccccc}
\hline Ano & Idade & $\boldsymbol{t}$ & $\boldsymbol{S}_{\boldsymbol{t}}$ & $\boldsymbol{B}_{\boldsymbol{t}}$ & $\mathbf{T}$ & Fator & VPEBF $_{\mathbf{t}}$ \\
\hline 2016 & 48 & 0 & $33.257,52$ & $15.457,49$ & 30 & 0,54 & $310.788,26$ \\
2017 & 49 & 1 & $35.202,44$ & $17.436,06$ & 31 & 0,58 & $318.785,30$ \\
2018 & 50 & 2 & $37.261,09$ & $19.542,75$ & 32 & 0,62 & $324.630,54$ \\
2019 & 51 & 3 & $39.440,14$ & $21.898,77$ & 33 & 0,66 & $330.187,41$ \\
$\mathbf{2 0 2 0}$ & $\mathbf{5 2}$ & $\mathbf{4}$ & $\mathbf{4 1 . 7 4 6 , 6 2}$ & $\mathbf{3 5 . 0 6 3 , 1 9}$ & $\mathbf{3 4}$ & - & $\mathbf{4 7 9 . 4 1 5 , 4 9}$ \\
2021 & 53 & 5 & $44.187,98$ & $36.890,47$ & 35 & - & $456.925,34$ \\
2022 & 54 & 6 & $46.772,12$ & $39.047,84$ & 36 & - & $437.663,83$ \\
2023 & 55 & 7 & $49.507,37$ & $41.083,33$ & 37 & - & $416.219,37$ \\
2024 & 56 & 8 & $53.402,59$ & $43.225,52$ & 38 & - & $395.344,95$ \\
2025 & 57 & 9 & $55.467,12$ & $45.480,03$ & 39 & - & $375.073,78$ \\
2026 & 58 & 10 & $58.710,86$ & $48.772,90$ & 40 & 1,02 & $362.197,33$ \\
2027 & 59 & 11 & $62.144,31$ & $54.984,48$ & 41 & 1,09 & $367.158,85$ \\
2028 & 60 & 12 & $65.778,54$ & $61.635,36$ & 42 & 1,16 & $369.553,27$ \\
2029 & 61 & 13 & $69.625,30$ & $69.114,52$ & 43 & 1,23 & $371.483,61$ \\
2030 & 62 & 14 & $73.697,02$ & $77.530,77$ & 44 & 1,31 & $372.930,73$ \\
2031 & 63 & 15 & $78.006,86$ & $87.006,56$ & 45 & 1,40 & $373.875,88$ \\
2032 & 64 & 16 & $83.468,74$ & $98.258,65$ & 46 & 1,50 & $376.468,21$ \\
2033 & 65 & 17 & $87.397,40$ & $110.355,35$ & 47 & 1,60 & $376.234,48$ \\
\hline
\end{tabular}

O Gráfico 2 representa a comparação entre o comportamento do VPEBF levando em conta a regra de aposentadoria 85/95 progressiva e a regra do fator. Esta comparação torna possível uma análise geral do impacto que a Regra 85/95 progressiva causa na idade ótima de aposentadoria, $x^{*}$. Observando o Gráfico 2, é possível notar que a partir dos 58 anos de idade seria mais vantajoso para a segurada optar pela regra do fator, visto que o fator previdenciário começa a assumir valores maiores do que 1, resultando em aumentos no cálculo de seu benefício, diferentemente da Regra 85/95, que continua isentando o fator do cálculo. Analisando apenas a progressão do VPEBF de acordo com a regra do fator, nota-se que a maximização ocorre aos 64 anos, com um montante esperado igual à $\mathrm{R} \$ 376.468,21$, momento em que o fator previdenciário atinge o valor de 1,50. 
Gráfico 2 - Regra 85/95 vs. Regra Fator.

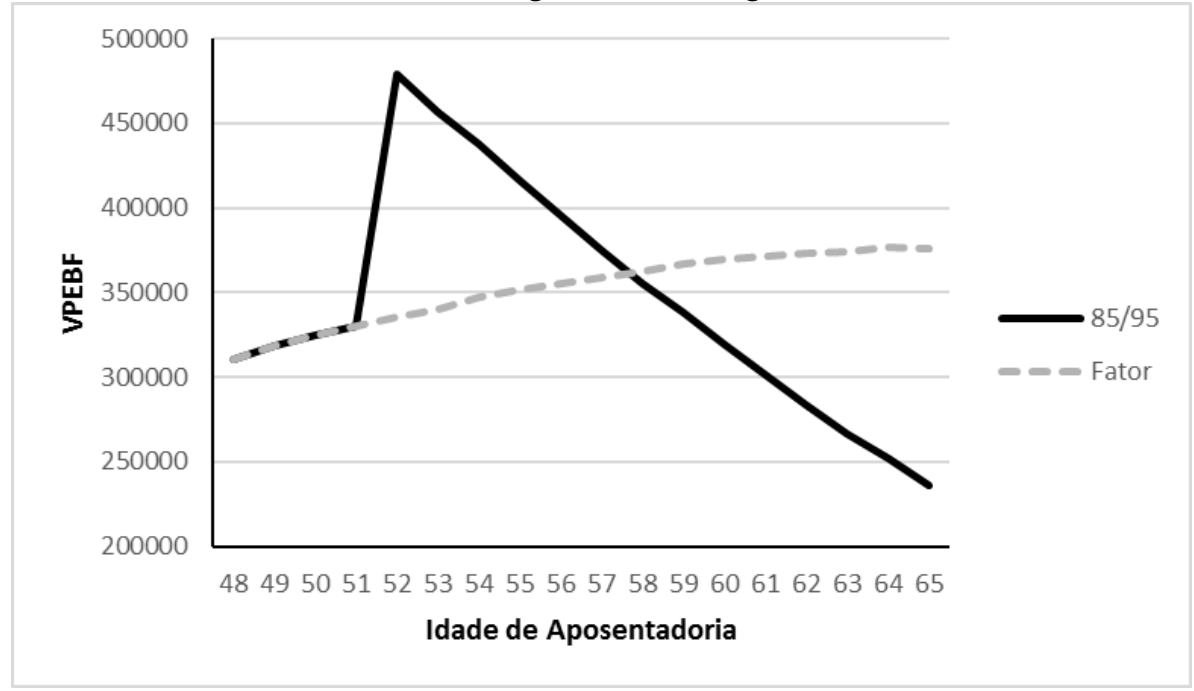

A regra de aposentadoria 85/95 progressiva, de acordo com as premissas expostas na Seção 3.4, além de diminuir em 12 anos o tempo que a segurada leva para atingir a maximização do VPEBF, tem o montante esperado aproximadamente 27,34\% maior do que o VPEBF máximo que seria alcançado se a aposentadoria fosse consumada apenas pela regra do fator. A Tabela 5 ilustra a diferença entre as regras de aposentadoria.

Tabela 5 - Regra 85/95 vs. Regra do Fator - Mulher.

\begin{tabular}{ccccc}
\hline Idade & Fator (85/95) & VPEBF (85/95) & Fator & VPEBF \\
\hline 48 & 0,54 & $310.788,26$ & 0,54 & $310.788,26$ \\
49 & 0,58 & $318.785,31$ & 0,58 & $318.785,31$ \\
50 & 0,62 & $324.630,55$ & 0,62 & $324.630,55$ \\
51 & 0,66 & $330.187,42$ & 0,66 & $330.187,42$ \\
52 & - & $479.415,49$ & 0,70 & $335.455,62$ \\
53 & - & $456.925,24$ & 0,74 & $340.412,93$ \\
54 & - & $437.663,83$ & 0,79 & $347.139,43$ \\
55 & - & $416.219,37$ & 0,84 & $351.460,83$ \\
56 & - & $395.344,95$ & 0,90 & $355.410,62$ \\
57 & - & $375.073,78$ & 0,96 & $359.004,79$ \\
58 & - & $355.364,23$ & 1,02 & $362.197,34$ \\
59 & - & $338.223,54$ & 1,09 & $367.158,86$ \\
60 & - & $319.543,01$ & 1,16 & $369.553,27$ \\
61 & - & $301.405,19$ & 1,23 & $371.483,62$ \\
62 & - & $283.817,05$ & 1,31 & $372.930,74$ \\
63 & - & $266.790,14$ & 1,40 & $373.875,89$ \\
64 & - & $251.787,79$ & 1,50 & $376.468,21$ \\
65 & - & $235.753,53$ & 1,60 & $376.234,48$ \\
\hline
\end{tabular}

\subsection{Análise de Sensibilidade}

Esta Seção tem como objetivo principal, a análise de comportamento da idade ótima de aposentadoria $\left(\mathrm{x}^{*}\right)$, quando alteramos individualmente os valores das variáveis: idade de entrada no mercado de trabalho (y), taxa de juros (i), expectativa de vida ao nascer e taxa de crescimento salarial (w), mantendo as demais variáveis apresentadas na Seção 3.4 constantes. Partindo ainda do princípio de que o segurado deseja maximizar o seu fluxo de benefícios futuros esperados, ou seja, que o 
contribuinte optará por se aposentar na idade ótima $x^{*}$. Ademais, será comparado simultaneamente os efeitos das variações para segurados do sexo masculino e feminino.

De antemão, devido a elegibilidade para aposentadoria por tempo de contribuição para contribuintes do sexo feminino ocorrer 5 anos mais cedo, assim como, a bonificação de 5 anos no tempo de contribuição no cálculo do fator previdenciário, nota-se que, em todos os cenários, segurados do sexo feminino, obtém a maximização de seu fluxo de benefícios futuros esperados de forma antecipada aos contribuintes de sexo masculino. Tal fato, também impacta no valor dos montantes de benefícios esperados, que para todos os cenários, são maiores para contribuintes mulheres.

\subsubsection{Idade de Entrada no Mercado de Trabalho}

Para analisar o impacto que mudanças na variável idade de entrada no mercado de trabalho (y) causam na idade ótima de aposentadoria $\left(x^{*}\right)$, seu valor, que na elaboração das premissas para $o$ cenário inicial do modelo foi fixado em 18 anos, sofrerá variações, enquanto as demais variáveis apresentadas na Seção 3.4 permanecem constantes. O estudo partirá da idade de entrada utilizada no cenário inicial e acrescentará, por vez, 1 ano até atingir a idade de 35 anos. O Gráfico 3 ilustra a análise do impacto que variações na idade de entrada no mercado de trabalho causam na idade ótima de aposentadoria.

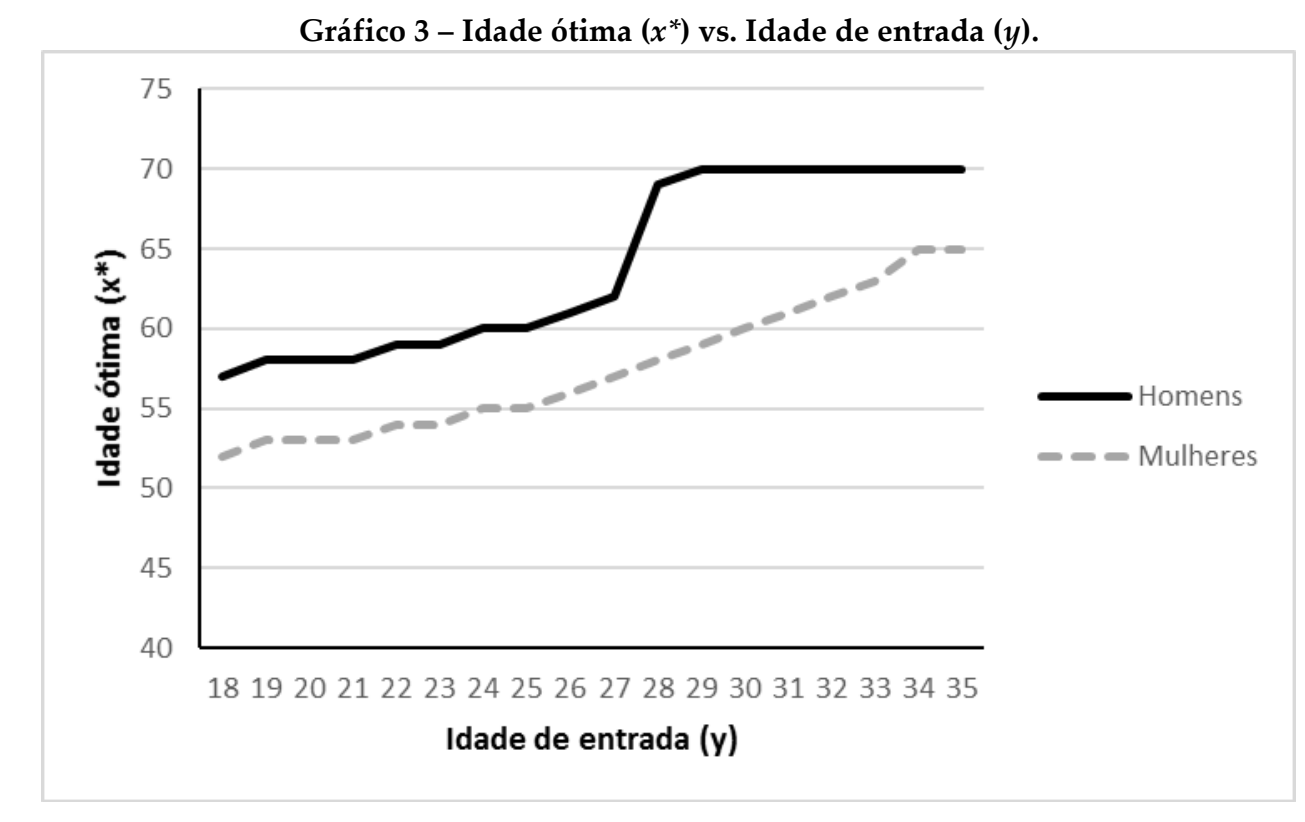

Observando o Gráfico 3, chega-se à conclusão de que quanto mais tarde o segurado entrar no mercado de trabalho, mais tarde atingirá a idade ótima de aposentadoria. A relação diretamente proporcional entre as variáveis é facilmente explicada pelo fato do contribuinte ter que trabalhar mais para se adequar às regras de aposentadoria, compensando assim, a sua entrada tardia no mercado de trabalho. Na medida em que as idades de entrada vão aumentando, as idades ótimas começam a convergir para as idades de aposentadoria compulsória, ou seja, 70 anos para homens e 65 para mulheres.

Observa-se também, que para os homens, entre as idades de entrada 18 e 27 anos, a regra de aposentadoria mais vantajosa na idade ótima é sempre a Regra 85/95, porém, a partir dos 28 anos, a Regra do Fator se torna mais proveitosa. No caso das mulheres, entre as idades de entrada 18 e 33 anos, a regra de aposentadoria mais vantajosa na idade ótima é a Regra 85/95, e a partir dos 34 anos, a Regra do Fator torna-se mais benéfica. 


\subsubsection{Taxa Real de Juros}

Para analisar o impacto que mudanças na taxa real de juros (i) causam na idade ótima de aposentadoria $\left(\mathrm{x}^{*}\right)$, seu valor, que na elaboração das premissas para o cenário inicial do modelo foi fixado em 3\% a.a., sofrerá variações, enquanto as demais variáveis apresentadas na Seção 3.4 permanecem constantes. O estudo partirá de uma taxa real igual a $0 \%$ a.a., ou seja, de uma taxa nominal de juros igual à taxa de inflação (apresentando um ganho real nulo), acrescentando por vez 1\% a.a., até atingir o valor real de $13 \%$ a.a. O Gráfico 4 expõe a análise do impacto que variações na taxa real de juros causam na idade ótima de aposentadoria.

Gráfico 4 - Idade ótima ( $\left.x^{*}\right)$ vs. Taxa real de juros (i).

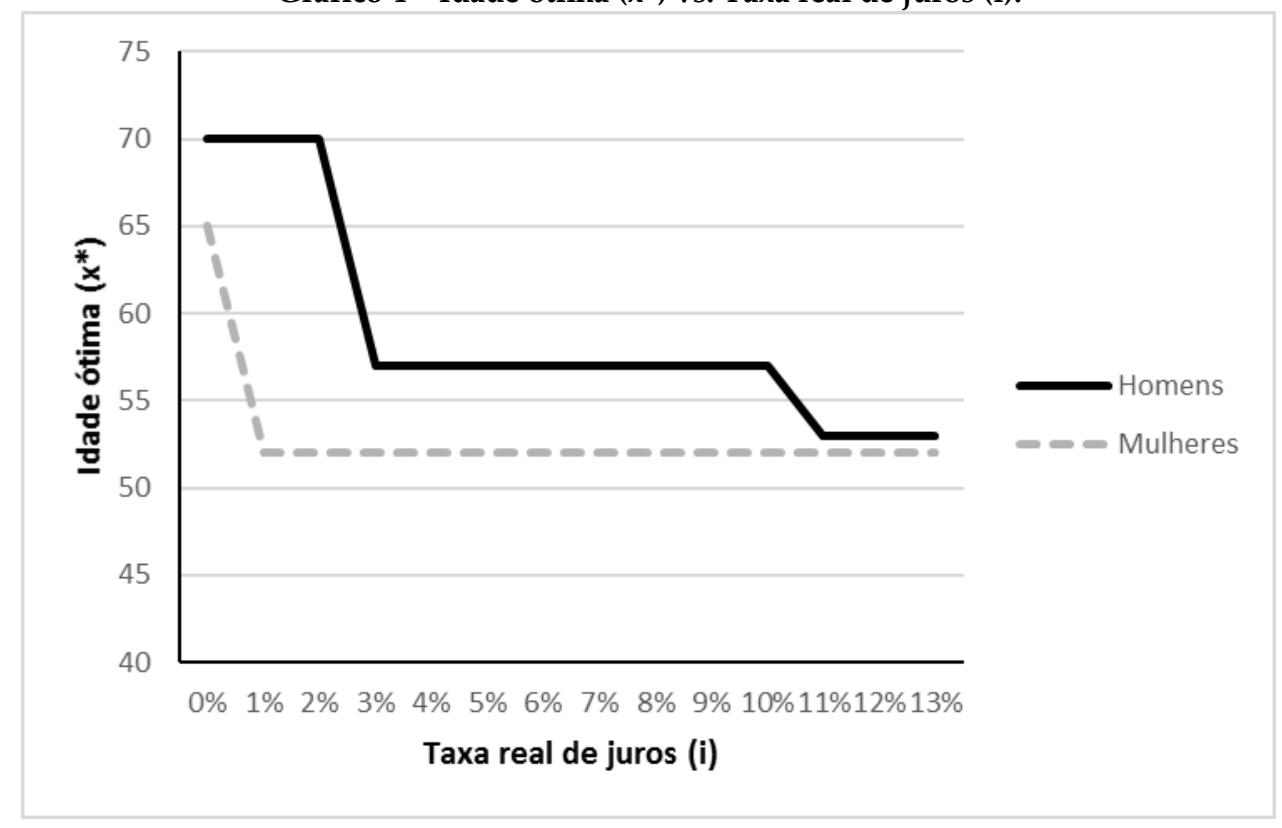

Observando o Gráfico 4, chega-se à conclusão de que aumentos na taxa real de juros, diminui a idade ótima para aposentadoria dos segurados. Um cenário com taxa real de juros nula equipara a idade ótima $\left(\mathrm{x}^{*}\right)$ à idade de aposentadoria compulsória, ou seja, 70 anos para homens e 65 anos para mulheres. À medida que a taxa de juros cresce, as idades ótimas vão diminuindo, passando a se igualar às idades conhecidas no cenário inicial (57 anos para homens e 52 para as mulheres) a partir de taxas de juros iguais a 3\% a.a. para homens e 1\% a.a. para mulheres. Apenas para contextos com taxa real de juros alta, ou seja, acima de $10 \%$ a.a. para homens e acima de $17 \%$ a.a. para mulheres, as idades voltam a diminuir, convergindo para as idades de elegibilidade para aposentadoria por tempo de contribuição dos segurados (53 anos para homens e 48 para mulheres).

A relação inversamente proporcional entre as variáveis é facilmente explicada através da equação (4), pois o valor do benefício $\left(B_{t}\right)$ aumenta à medida que o segurado continua trabalhando. Tal aumento, atrelado a uma taxa real de juros igual a $0 \%$ a.a., faz com que se torne mais vantajoso para o segurado uma aposentadoria tardia, visto que, o VBEPF passará a ser atualizado apenas sob as probabilidades de recebimento dos benefícios, diferentemente de cenários com taxa de juros mais alta, que torna mais atrativo uma aposentadoria precoce.

\subsubsection{Expectativa de Vida ao Nascer}

Para analisar o efeito que variações na expectativa de vida ao nascer causam na idade ótima de aposentadoria $\left(x^{*}\right)$, foi necessário agravar e desagravar a Tábua Completa de Mortalidade para ambos os sexos - IBGE 2013, extrapolada pelo MPS para idades acima de 80, com o objetivo de atingir as expectativas de vida ao nascer desejadas. Admitindo um erro menor do que 1\% (3,65 dias), o estudo partirá da mais recente expectativa de vida ao nascer conhecida até então (considerada nas 
premissas iniciais do modelo), 75,2 anos, extraída da Tábua Completa de Mortalidade - IBGE 2014, variando esta expectativa entre 50,2 e 100,2 anos, de 5 em 5 anos, mantendo as demais variáveis expostas na Seção 3.4 constantes.

Conforme ilustra o Gráfico 5, com uma expectativa de vida ao nascer muito baixa (entre 50,2 e 55,2 anos), a idade ótima para aposentadoria se equipara às idades de elegibilidade para aposentadoria por tempo de contribuição dos segurados (53 anos para homens e 48 anos para mulheres), pois, visto que com uma menor expectativa de sobrevida, é preferível optar por uma aposentadoria precoce, mesmo que esta escolha resulte em perdas econômicas no cálculo do benefício $\left(B_{t}\right)$ do segurado.

Com os acréscimos na expectativa de vida ao nascer, nota-se um aumento na idade ótima de aposentadoria, atingindo um máximo de 64 anos para homens e 54 anos para as mulheres. Esses aumentos estão atrelados ao fator previdenciário, que para baixas expectativas de sobrevida, assumem rapidamente valores maiores do que 1, incentivando o segurado a trabalhar um pouco mais para atingir o VPEBF máximo, ao invés de se aposentar mais cedo, quando preenche os requisitos da Regra 85/95 (57 anos para homens e 52 anos para mulheres).

Gráfico 5 - Idade ótima $\left(x^{*}\right)$ vs. Expectativa de vida ao nascer.

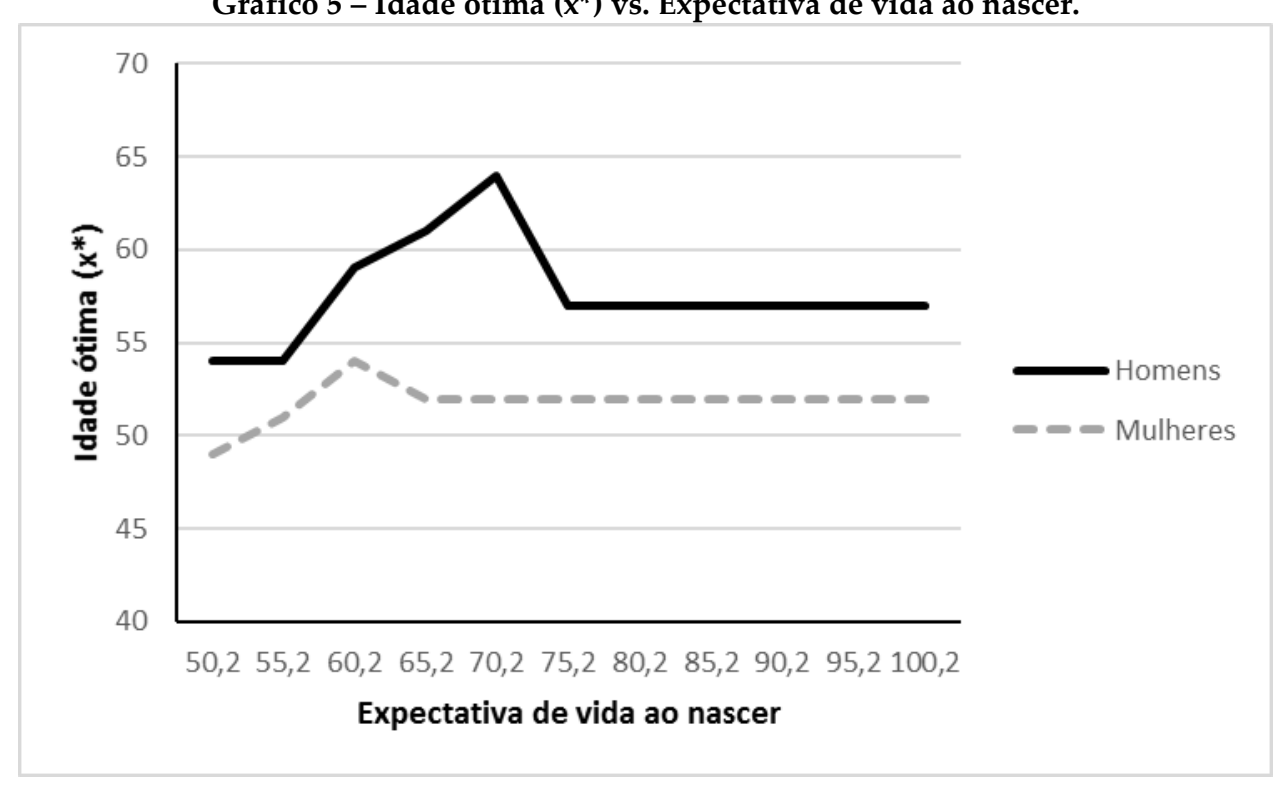

Quando a expectativa de vida ao nascer é maior do que ou igual a expectativa utilizada no cenário inicial, para homens, a idade ótima de aposentadoria começa a convergir para a idade conhecida na Seção 4.1 (57 anos), pois fazem o segurado se enquadrar da melhor forma possível na respectiva regra de aposentadoria, aumentando apenas, o tempo esperado de recebimento do benefício pelo segurado. Já para as mulheres, a idade ótima de aposentadoria retorna ao valor conhecido nos resultados iniciais (52 anos), um pouco mais cedo, a partir de uma expectativa de vida ao nascer de 65,2 anos.

\subsubsection{Taxa Real de Crescimento Salarial}

Para analisar o impacto que mudanças na taxa real de crescimento salarial (w), causam na idade ótima de aposentadoria $\left(x^{*}\right)$, seu valor, que na elaboração das premissas para o cenário inicial do modelo foi fixado em 1,97\% a.a. para homens e 1,29\% a.a. para mulheres, sofrerá variações enquanto as demais variáveis apresentadas na Seção 3.4 permanecem constantes. O estudo partirá de uma taxa real igual a $0 \%$ a.a., ou seja, de uma taxa nominal igual à taxa de inflação (apresentando um ganho real nulo), acrescentando por vez $1 \%$ a.a., até atingir o valor real de $13 \%$ a.a. O Gráfico 6 
expõe a análise do impacto que variações na taxa real de crescimento salarial causam na idade ótima de aposentadoria.

Gráfico 6 - Idade ótima $\left(x^{*}\right)$ vs. Taxa real de crescimento salarial (w).

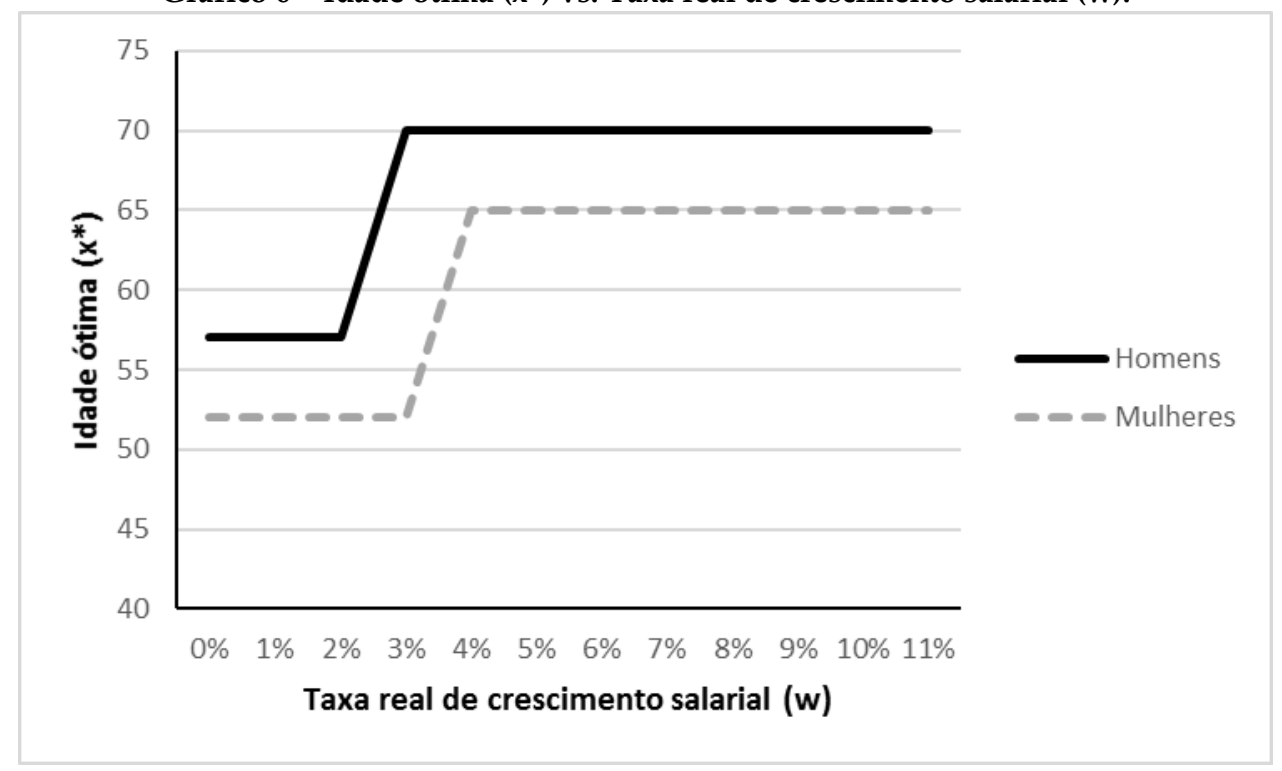

Observando o Gráfico 6, chega-se à conclusão de que aumentos na taxa real de crescimento salarial, de acordo com as premissas expostas na Seção 3.4, aumentam a idade ótima para aposentadoria dos segurados. Contextos com taxa real de crescimento salarial entre $0 \%$ a.a. e $2 \%$ a.a. para homens e $0 \%$ e $3 \%$ a.a. para mulheres, resultam nas idades ótimas iguais às encontradas no cenário inicial (57 anos para homens e 52 anos para mulheres). Na medida em que a taxa de crescimento salarial aumenta, as idades passam a convergir para as idades de aposentadoria compulsória, ou seja, 70 anos para homens e 65 anos para mulheres. Este comportamento pode ser explicado através de dois aspectos: aumento do fator previdenciário e aumento da média aritmética real dos $80 \%$ maiores salários de contribuição, que ocasionam um acréscimo direto no cálculo do benefício $\left(B_{t}\right)$ do contribuinte.

\section{CONCLUSÃO}

A decisão de se aposentar passa por diversas etapas e variáveis imensuráveis, porém, se o objetivo do contribuinte for maximizar o seu fluxo de benefícios esperados de aposentadoria, uma análise sob a ótica da matemática atuarial pode ser realizada. As dúvidas e incertezas acerca do melhor momento para se aposentar vão além de questões individuais, podendo ser facilmente influenciado por diferentes contextos econômicos, o que ressalta a importância de uma economia estável e de uma maior percepção por parte do segurado de que tais aspectos são fundamentais na escolha entre se aposentar e continuar trabalhando.

Considerando as premissas iniciais expostas na Seção 3.4, a idade que maximiza o fluxo de benefícios de um indivíduo caracterizado na forma de segurado no RGPS, de acordo com as regras atuais de aposentadoria é de 57 anos para homens, com um montante esperado de $\mathrm{R} \$ 390.220,93$, e de 52 anos para mulheres, com um montante esperado de $\mathrm{R} \$ 479.415,49$. Quando analisado apenas pela regra de aposentadoria do fator previdenciário, a idade ótima aumenta para 69 anos para homens e 64 para mulheres, com montantes esperados iguais a $R \$ 368.396,72$ e $R \$ 376.468,21$, respectivamente. Além disso, sendo o fator previdenciário inversamente proporcional à expectativa de vida (que tende a aumentar no decorrer dos anos), os resultados obtidos permitem pressupor que a disparidade entre a regra 85/95 e a regra do fator, aumentará, ou seja, a tendência é que, com o passar dos anos, a regra de aposentadoria que maximiza o VPEBF continue sendo a regra 85/95 progressiva. 
Quando observada de acordo com aumentos na expectativa de vida ao nascer, a idade ótima se mantém praticamente constante para ambos os sexos, já com relação à taxa real de crescimento salarial, observa-se um comportamento inversamente proporcional entre $0 \%$ a.a. e $2 \%$ a.a., e diretamente proporcional entre $4 \%$ a.a. e $11 \%$ a.a. Resultado diferente é visto quando ocorrem alterações na taxa real juros que, para ambos os sexos, se comporta de forma inversamente proporcional em todo intervalo analisado.

O fato da elegibilidade para aposentadoria por tempo de contribuição de segurados do sexo feminino ocorrer 5 anos mais cedo, atrelado ao fato da bonificação de 5 anos de contribuição no cálculo do fator previdenciário, faz com que a idade que maximiza o fluxo esperado dos benefícios futuros para mulheres seja sempre menor do que para homens. Essa diferença, também ocorre nos valores dos montantes esperados pelo segurado, que por tais fatos, tornam os valores maiores para contribuintes do sexo feminino em todos os cenários.

No momento da aposentadoria, cada contribuinte tem seus critérios e prioridades para tomar sua decisão, porém, se o critério utilizado for à maximização do montante esperado de seus benefícios, a Regra 85/95 progressiva, ao que o estudo aponta, estimula uma aposentadoria mais precoce quando comparada com a regra anterior, o que vai na contramão do que é esperado para sustentabilidade financeira-atuarial do Regime Geral de Previdência Social, devido a mudanças demográficas, que apontam no sentido oposto. O estudo ajuda na compreensão de que mudanças na legislação previdenciária são, de todo modo, bastante impactantes na vida dos trabalhadores, tanto individualmente, quanto coletivamente, mostrando que, decisões precipitadas por parte do governo podem gerar prejuízos às contas públicas, colocando em cheque o sentido amplo da seguridade social.

Fica o desejo futuro de aprofundar o estudo com o objetivo de analisar o impacto que propostas em debate pelo governo do presidente Michel Temer, causariam na idade que maximiza o fluxo de benefícios de aposentadoria de um segurado vinculado ao RGPS.

\section{REFERÊNCIAS}

BARBOSA, V. A. Previdência Social brasileira: breve relato da origem e principais mudanças ocorridas nos últimos anos. In: Âmbito Jurídico, Rio Grande, XVI, n. 119, dez 2013.

BRASIL. Constituição da República Federativa do Brasil de 1988. Disponível em: http://www.planalto.gov.br/ccivil_03/constituicao/constituicao.htm. Acesso em: 10 maio 2016.

BRASIL. Ministério da Previdência e Assistência Social (MPAS). Livro Branco da Previdência Social. Brasília: MPAS/GM, dez. 2002.

BROWN, R. L. Designing a social security pension system. International Social Security Review, v. 61, v. 1, p. 61-79, 2008.

CASTRO, C. A. P.; LAZZARI, J. B. Manual de Direito Previdenciário. 14. ed. Florianópolis: Modelo, 2012.

CENTRAL ÚNICA DOS TRABALHADORES - CUT. Apostila do Curso de Formação Sindical, 1989.

COUTO, B. R. O Direito Social e a Assistência Social Brasileira: uma equação possível? 8. ed. São

Paulo: Cortez, 2000. 
FILIPPO, F. Os princípios e objetivos da Seguridade Social, à luz da Constituição Federal. In: Âmbito Jurídico, Rio Grande, X, n. 43, jul. 2007. Disponível em: http://www.ambitojuridico.com.br/site/index.php?n link=revista artigos leitura\&artigo id=2012. Acesso em: 27 mar. 2016.

GEORGE, L. K. Handbook of aging and the social sciences. Social factors an illness. In R. H Binstock \& L. K. George. 4th ed. San Diego: Academic Press. 1996.

GIAMBIAGI, F.; AFONSO, L. E. Cálculo da alíquota de contribuição previdenciária atuarialmente equilibrada: uma aplicação ao caso brasileiro. Rev. Bras. Econ., Rio de Janeiro, v. 63, n. 2, abr./jun. 2009.

KERTZMAN, I. Curso prático de Direito Previdenciário. 8. ed. rev. e atual. Salvador: JusPodivm, 2011.

MAGALHÃES, M. O.; KRIEGER, D. V.; VIVIAN, A. G.; STRALIOTTO, M. C. S.; POETA, M. P. Padrões de ajustamento na aposentadoria. Revista Aletheia, v. 1, n. 19, p. 57-68, 2004.

MARTINS, S. P. Direito da Seguridade social. 29. ed. São Paulo: Atlas, 2010.

MONTEIRO, C. Como funciona a previdência social. 2014. Disponível em: http://pessoas.hsw.uol.com.br. Acesso em: 27 mar. 2016.

NOLASCO, L. O fator previdenciário. In: Âmbito Jurídico, Rio Grande, XV, n. 105, out 2012. Disponível em: http://www.ambito-juridico.com.br/site/?n link=revista artigos leitura\&artigo id=12318. Acesso em: 1 abr. 2016.

OLIVA, M. S. Trabalho e previdência social. Intertemas - ISSN 2176-848X. Disponível em: http://intertemas.unitoledo.br/revista/index.php/INTERTEMAS/article/viewFile/2613/2402. Acesso em: $1 \mathrm{abr}$. 2016.

PENAFIERI A. C.; AFONSO, L. E. O impacto da mudança da regra de cálculo das aposentadorias por tempo de contribuição do INSS: O fator previdenciário é atuarialmente justo? Economia Aplicada, v. 17, n. 4, p. 667-694, 2013.

SALVADOR, E. Implicações da reforma da previdência sobre o mercado de trabalho. Serviço Social $\mathcal{E}$ Sociedade, São Paulo, ano 16, n. 81, p. 7-39, mar. 2005.

SERRA; GURGEL, J. B. Evolução da previdência social. Sindicato nacional dos editores de livros -RJ, 2008. 